\title{
Back-up Power Generation using Bicycle
}

\author{
Manish Paul ${ }^{1}$, Kashyap Kumar Nath ${ }^{2}$, Sangeeta Kalita ${ }^{3}$ \\ Assistant Professor, Electrical Engineering Department, Girijananda Chowdhury Institute of Management and \\ Technology, Guwahati, Assam, India ${ }^{1}$ \\ UG Student, Electrical Engineering Department, Girijananda Chowdhury Institute of Management and Technology, \\ Guwahati, Assam, India ${ }^{2,3}$
}

\begin{abstract}
The objective of this project is to design, build and be able to present a mechanism that will produce ac power using the mechanical energy produced by a person pedalling a standard bicycle. Also we would like to be able to show the user and the audience the advantage of using fluorescent bulbs, and in doing so, make more conscience of energy saving products. The crucial part of this project is being able to take the variable DC voltage that is produced by the variable pedalling speed and converting it to a stable $12 \mathrm{~V} \mathrm{DC}$ output that can be converted to AC power through an inverter.
\end{abstract}

Keywords: Alternator, Inverter, Battery charging, Transformer.

\section{INTRODUCTION}

India is the second most popular nation in the world. People use bicycles as the main medium of transportation in villages. In addition in cities, where most people use exercise bikes, the energy can be productively used to power electronic gadgets, which require less power.

In India, many of the villages are still without electricity and most of them use bicycle as their medium of transportation. In such places, our system will be of great help. Charging of the battery can be done by a layman by just connecting the circuit to the output of the alternator which is connected to the bicycle. This would charge the batteries. World is a storehouse of energy. And according to energy conversion law, energy neither be created nor be destroyed but can be transformed from one form to another. But we are wasting resources that can produce energy as if they are limited. Humans are able to generate approximately $150 \mathrm{~W}$ of power while riding bicycle. However, this power goes waste without any use. If this is making use of this energy, would be able to power many electronic devices. An alternator can be used for harvesting the energy generated by a cycle rider while riding. We can charge mobile phones or a small lighting device with the power.

\section{PROJECT APPLICATION}

The applications for the project would be simple in the initial phases. This would supply energy for simple appliances like light bulbs for rooms, fans, and small pumps for running water from wells. This project focuses on a human powered bicycle generation. The bike will be connected to a motor that generates energy to be used directly or stored in batteries for later use. While solar, wind, and water generated energy are also sustainable, our human powered energy has a few unique properties related. The first is that human power is the only truly independent form of power generation. Wind, water, and solar energy are all at the will of nature; however, our system will always be available to produce energy if an able body is around. This on demand energy will always be available to provide energy for an item in an emergency situation, if all the other generators fail to provide energy Another great aspect of the human powered generator is the awareness it could instill in the users, as they will be able to observe and appreciate the energy they are making for themselves.

\section{BASIC BLOCK DIAGRAM}

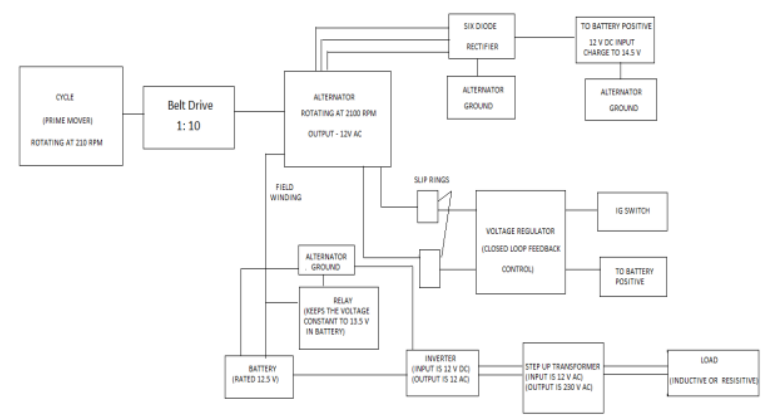

The basic design for the bicycle powered generator is to have a bicycle on a fixed stand, and then when the bicycle is pedalled, the spinning motion of the rear tire is used to produce mechanical energy directly into a DC voltage.

A bicycle is designed to convert human energy into mechanical energy for transportation purposes. The mechanical energy is then converted into electrical energy through the use of a drive train turning a motor. It is an efficient design that provides seating for the user as well as pedals and drive train that are easily activated. To connect the wheel to the motors axel a simple DC motor was initially thought to be the best choice as the DC output 
of the motor was the desired electrical output for the battery array. The diode is connected which is allowing current to flow from the motor to the battery. The cathode should be pointing towards the positive terminal of the battery. The battery should be connected in series with the motor and diode. An adapter is used to connect the battery to the inverter; inverter will convert the $12 \mathrm{~V}$ dc to $\mathrm{AC}$ which is step up using a transformer. Once the motor is secured to the belt, we will need to use a multi meter to measure how much voltage is being exerted while the pedal. Depending on how much we exert, we will be able to power small appliances.

\section{METHODOLOGY}

\section{Project implementation steps:}

i) The back tyre of the bicycle is removed. Since the only part of the bicycle that needs to work is the chain and pedals, a junk bike or an old used bike would work just fine.

ii) A stand is built to elevate the bicycle off the ground.

iii) A drive belt is attached along the back rim.

iv) The car alternator is attached to the stand.

v) The battery leads is connected to the inverter.

vi) The output power from the inverter is step up using a transformer.

vii) The appliance need to be powered up is connected through the inverter.

\section{Project Implementation tools:}

1) The Bicycle: It is the prime mover of the alternator. It is run manually at around $210 \mathrm{rpm}$.

2) The bicycle stand: The stand keeps the bike elevated and secure. The stand is built so that the rear wheel of the bike is about 5-7 inches off the ground.

3) Drive belt: A belt drive is used to couple the bicycle and the alternator. Also to speed is increased upto 10 times i.e. $2100 \mathrm{rpm}$

\section{4) Pulley}

5) Alternator: It gives a 12 volts dc output with $60 \mathrm{amps}$. The stator contains 3-phase winding and laminated sheets in order to reduce hysteresis and iron losses. A 2 amps in the filed winding will give rise to 60amps in the armature windings with a 12 volts dc in the field winding.

6) Rechargeable battery sealed lead acid battery: We have used a 12 volt / $80 \mathrm{amp}-\mathrm{hr}$. with rated 8 amps lead acid battery (rechargeable). We are used the battery for two purpose: 1) for supply the field and 2) for regulating the load. The alternator charges the battery.

7) Inverter circuit: The main purpose of inverter in our circuit is to convert the dc voltage of battery to ac voltage. One end of the inverter is connected to the positive of the battery and the other is connected to the ground of the alternator. We are using a pair of resistor and capacitor in order to create the pulsating frequency. We are using a 100 ohms resistor in order to protect the inverter circuit from the high current if any. We are using two MOSFETs in order to give the positive half and negative half from the pulsating frequency of the ac voltage.
8) Transformer: Here we are using a step up transformer which steps up the 12 volts of the inverter to 230 volts, 240 volts, 250 volts, 260 volts respectively by giving equivalent tapping in the secondary winding. This transformer is a type of auto transformer where we can get several output voltages by regular tapping on the transformer.

9) Relay circuit: Here we are using the relay as an on/off switch in order to protect the battery from over charging. It contains a voltage analyzing circuit for quick checking of voltage before start of charging since over charging may damage the battery. The voltage analyzer gives a visual indication of the voltage level at which the battery requires immediate charging.

\section{WORKING PRINCIPLE}

In the project we have used the car alternator as emergency power supply. It gives a 12 volts dc output with 60amps. The stator contains 3-phase winding and laminated sheets in order to reduce hysteresis and iron losses. It is made up of silicon steel in order to reduce eddy current losses. The stator contains the armature windings and the rotor contains field sensing windings. A 2 amps in the filed winding will give rise to 60amps in the armature windings with a 12 volts $\mathrm{dc}$ in the filed winding. It is given for synchronizing the rotor magnetic field and stator rotating magnetic field in order to make the machine a synchronous machine. At the output of the alternator we have a six bridge diode rectifier to convert ac to dc.

The current produces by the alternator goes to the battery via the battery wire. As a whole the VR controls the field current by sensing the battery voltage. And it also controls the output voltage of the alternator when the load on it increases the VR increases the field current to the alternator in order to keep the battery voltage constant. It acts as a current dependent source the VR acts as the closed loop control. Whenever the battery voltage drops under 12 volts it gives full rated current to the alternator and when it drops it gives the current i.e. the field current the amount which is enough to meet the total load. The two slip rings $\mathrm{F} 1$ and $\mathrm{F} 2$ can be connected to the battery either by connecting F1 to the battery and the VR controls the field current by sensing the sourcing voltage or by connecting F1 to ground and the VR controls the field current through the sinking voltage.

\section{RESULT}

\begin{tabular}{|c|c|c|c|c|c|}
\hline $\begin{array}{c}\text { S1. } \\
\text { No } \\
\cdot\end{array}$ & $\begin{array}{c}\text { Bicycle } \\
\text { Speed } \\
\text { (rpm) }\end{array}$ & $\begin{array}{c}\text { Alterna } \\
\text { tor } \\
\text { speed } \\
(\mathrm{rpm})\end{array}$ & $\begin{array}{c}\text { Alterna } \\
\text { tor } \\
\text { Voltag } \\
\text { e (V) }\end{array}$ & $\begin{array}{c}\text { Boltage } \\
\text { (V) }\end{array}$ & $\begin{array}{c}\text { Inverte } \\
\text { r } \\
\text { Output }\end{array}$ \\
\hline 1 & 105 & 1110 & 12.8 & 12.8 & 230 \\
\hline 2 & 210 & 1706 & 13.2 & 13.2 & 256 \\
\hline 3 & 310 & 2448 & 14.5 & 14.5 & 283 \\
\hline 4 & 350 & 2678 & 14.5 & 14.5 & 290 \\
\hline
\end{tabular}




\section{CONCLUSION}

With the rotation of the cycle at $210 \mathrm{rpm}$ which is acting as a prime-mover, this rotation will subsequently converting the output voltage of the car alternator which is $12 \mathrm{~V} \mathrm{dc}$ to $12 \mathrm{~V}$ ac which is being step up by the transformer to $230 \mathrm{~V}$ ac. This output power is given to the subsequent load.

\section{REFERENCES}

[1] Michael MazgaSabavalla, Ravi Kuchimanchi, "Pedal Powered Electricity Generator" pp-2-7, July 2010.

[2] Rajesh Kannan, Meggalingam, Pranay, Sreethara, Vrilliyara, Raghavendra Murli Prabhu, Rocky Katoh, "Pedl Powered Generation", IJAER, ISSN 0973-4562 Vol 7 No.11, 2012

[3] BradlyPelz and Jefferey Feiereisen, "Bicycle Powered Generator for the University Farm" Thesis pp-8-22

\section{BIOGRAPHIES}

Manish Paul: Presently working as Asst. Prof. in Girijananda Chowdhury Institute of Management and Technology. Did his Bachelor degree from NERIST and Master degree from NIT Agartala.

Kashyap Kumar Nath: Undergraduate student of Electrical Engineering in Girijananda Chowdhury Institute of Management and Technology.

Sangeeta Kalita: Undergraduate student of Electrical Engineering in Girijananda Chowdhury Institute of Management and Technology. 